\title{
Effect of Different Formulations on Characteristic of Biobased Alginate Edible Films as Biodegradable Packaging
}

\author{
Novia Racmayani and Amir Husni* \\ Department of Fisheries, Faculty of Agriculture, Universitas Gadjah Mada, Yogyakarta 55281, \\ Indonesia
}

\begin{abstract}
Edible film can be used for food packaging. The main raw materials for edible film were alginates and plasticizers including glycerol and olive oil. This study aims to determine the characteristics of edible film composed of alginate, glycerol and olive oil. The study was carried out through the manufacture of edible films composed of alginates with various concentrations $(2,3,4,5$ and $6 \%, \mathrm{w} / \mathrm{v}), 10 \%$ glycerol and $0.01 \%$ olive oil. Characteristics of edible film was observed including thickness, tensile strength, water vapor transmission rate, solubility and elongation. The results showed that the products met the edible film standard of the Japanese Industrial Standard. Concentration of alginate used had significant effect on thickness, tensile strength, solubility and elongation of the edible film. The films with $6 \%$ concentration of alginate showed optimum results with thickness $0,227 \pm 0,008 \mathrm{~mm}$, tensile strength $3,097 \pm$ $0,384 \mathrm{MPa}$, elongation $86,682 \pm 5,090 \%$, solubility $8,690 \pm 2,892 \%$ and water vapor transmission rate $45,477 \pm 6,262 \mathrm{~g} / \mathrm{m} 2 / 24 \mathrm{~h}$.
\end{abstract}

\section{Introduction}

The use of plastic as a food wrap is a common thing for society. This result in more plastic waste being produced which impacts can damage the environment and cause pollution. Indonesia is ranked second in the world of plastic waste producers [1]. To reduce the problem of plastic waste, one of them is edible film from alginate. Alginate is a component of the polysaccharide obtained from brown algae. Alginate has the characteristics of forming a gel, biodegradable, biocompatible and toxic free so that it can be used as a mixture of several food products, pharmaceuticals, textiles and industrial waste [2]. Alginate can also be used as an ingredient for edible film. However, the properties of

* Corresponding author: $\underline{\text { a husni@ugm.ac.id }}$ 
alginate edible films are easily brittle so it needs to be added plasticizers to increase their flexibility. Edible film requires low molecular weight plasticizers to increase flexibility and durability, by interrupting polymer chain interactions and decreasing the temperature of transition glass [3].

Some studies on making edible films from alginates have been carried out by Santana and Kiechbusch [2] but cannot be used as easily damaged packaging materials in watery or humid environments. Therefore, further research is needed to develop the production of edible film by adding hydrophobic materials to improve moisture, reduce water absorption and moisture permeability so that it can be used as packaging material.

According to Manab [4], the use of lipids for the manufacture of edible films can increase the moisture in edible films because lipids are hydrophobic. Based on the research of Pereda et al. [5], giving olive oil to chitosan edible film can reduce water absorption and water vapor permeability which is inversely proportional to the addition of olive oil concentration. The production of edible film alginate with the addition of glycerol and olive oil as plasticizers is expected to increase the flexibility and the permeability of the film. However, it is necessary to add plasticizers with the optimum concentration to produce edible films that match the characteristics. Therefore, this study was conducted to determine the characteristics of alginate edible films based on variations in the concentration of alginate used.

\section{Materials and method}

\subsection{Materials}

The material used was sodium alginate (Multi Kimia Raya, Semarang), distilled water, extra virgin olive oil (Bertoulli), glycerol, $\mathrm{CaCl}_{2}$ (Progo Mulyo, Yogyakarta) and ethanol (Merck). The equipment used in the manufacture of edible films were glass plates, hot plate stirrers (AREC T VELP SCIENTIFICA F20500051), glass cups, ovens (EYELA WFO-601 SD), analytical scales (OHAUS NVT10001/3), spatulas, measuring cups. The equipment needed to test the characteristics of edible film were micrometer, Erlenmeyer (Iwaki) and Universal Testing Machine instrument (Toyo).

\subsection{Preparation of edible film}

The research was conducted by making alginate edible film which refers to the method of Anward et al. [6] with modification, namely dissolving sodium alginate in distilled water with variations in the concentration of alginate $2 \% \mathrm{w} / \mathrm{w}, 3 \% \mathrm{w} / \mathrm{w}, 4 \% \mathrm{w} / \mathrm{w}, 5 \% \mathrm{w} / \mathrm{w}$ and $6 \% \mathrm{w} / \mathrm{w}$ based on the volume of solution. then the solution was stirred until homogeneous at room temperature. Next, $10 \%$ glycerol was added to the alginate solution and stirred until homogeneous. $0.01 \%$ olive oil which had been dissolved in pure ethanol was then added to the alginate solution and stirred again until homogeneous. The alginate solution was printed on a glass plate measuring $15 \mathrm{~cm}$ x $20 \mathrm{~cm}$ with a thickness of $0.3 \mathrm{~mm}$. The mold was dried at $50^{\circ} \mathrm{C}$ for 24 hours. After that the film was immersed in $4 \% \mathrm{CaCl}_{2}$ solution for \pm 10 minutes and dried again in the oven. The formed film was stored and followed by testing the characteristics of the film. 


\subsection{Characterization of edible film}

\subsubsection{Thickness of edible film}

The thickness test of this edible film refers to Aleman et al. [7]. The film thickness was measured using a micrometer with a precision of $0.001 \mathrm{~mm}$. Measurements were made at five different places to get the average thickness representing the sample.

\subsubsection{Tensile strength}

The tensile strength testing process is carried out using Universal Testing Machine based on Setiani et al. [8]. Testing is done by cutting the sample into a paddle shape, then the tip of the sample is clamped by the tensile testing machine. Next, record the thickness and initial length of the sample. The start button on the computer is pressed and the tool will pull the sample at a speed of $100 \mathrm{~mm} /$ minute until the sample breaks. The tensile strength value was obtained from the results of the maximum stress distribution with cross-sectional area. The cross-sectional area was obtained from the results of multiplying the initial length of the sample with the initial thickness of the sample. Tensile strength tests were carried out on two samples of edible film which were then averaged. Tensile strength was calculated by the following equation:

$$
\tau=\frac{F \max }{A}
$$

\subsubsection{Elongation}

Measurement of elongation was carried out based on Setiani et al. [8] in the same way as testing tensile strength. The elongation was expressed as a percentage, calculated by:

$$
\text { Elongation }(\%)=\frac{\text { strain at breaks length }(\mathrm{mm})}{\text { initial length }(\mathrm{mm})} \times 100 \%
$$

\subsubsection{Total soluble matter}

Solubility testing was carried out based on Pereda et al. [5], expressed as a percentage of dry weight of the film dissolved in distilled water for 24 hours. Parts of each sample (m0) were weighed with accuracy of $\pm 0,0001 \mathrm{~g}$ and then immersed in $30 \mathrm{ml}$ distilled water for 24 hours. After soaking, the sample was dried at $105^{\circ} \mathrm{C}$ for 24 hours to measure the weight of the insoluble material (mf). Solubility calculations are carried out with the following calculations:

$$
\operatorname{TSM}(\%)=\frac{m 0-m f}{m 0} \times 100 \%
$$




\subsubsection{Water vapor transmission rate}

The vapor transmission rate of edible film was measured by dessicant method using the cup and determined by gravimetric according to the ASTM E96-95 [9] method. Before being measured, edible film is cut into a circle with a diameter according to the surface diameter of the cup, the thickness of the film is measured using a micrometer, then conditioned in a room with a temperature of $25^{\circ} \mathrm{C}, \mathrm{RH} 75 \%$ for 24 hours.

\section{Results and discussion}

\subsection{Thickness of edible film}

The thickness size of edible film can be influenced by the nature and content of the polymer that composes it [10]. According to Tavassoli-Kafrani [11], the composition of the alginate monomer affects the gel formation. The higher the concentration of alginate, the more polymers will be formed, which resulted in the thicker gel and film obtained. The thickness of the film originating from the liquid form can be influenced by the method of manufacture and the drying process [12]. The method used to control the thickness of the film produced in this study is by pouring the same volume of edible film mixture in each mold.

Table 1 shows that the difference in alginate concentration significantly affects the thickness of the edible film. The highest thickness of edible film was obtained in the treatment of $6 \%$ alginate with a value of $0.227 \pm 0.008 \mathrm{~mm}$; followed by treatment of $5 \%$ alginate with a value of $0.167 \pm 0.083 \mathrm{~mm}$; treatment of $4 \%$ alginate with a value of 0.142 $\pm 0.008 \mathrm{~mm}$; treatment of $3 \%$ alginate with a value of $0.088 \pm 0.008 \mathrm{~mm}$; and the lowest thickness of edible film was obtained in the treatment of $2 \%$ alginate with a value of 0.058 $\pm 0.008 \mathrm{~mm}$. According to Setyaningrum et al. [13], the thickness standard for edible films is not more than $0.25 \mathrm{~mm}$, so for the thickness parameters of edible film with all alginate concentrations in accordance with the standard. Thickness alginate film in this study was thicker than that in the study of Galus and Lenart (2013) [12] between $0.0125 \pm 0.0021 \mathrm{~mm}$ to $0.0268 \pm 0.0022 \mathrm{~mm}$ and also thicker than that in the Santana and Kieckbusch studies [2] with thicknesses between $0.0100 \pm 0.001 \mathrm{~mm}$ to $0.0140 \mathrm{~mm} \pm 0.001 \mathrm{~mm}$. 
Table 1. Effect of alginate concentration on characteristic of composite alginate/glycerol/ olive oil edible film

\begin{tabular}{|c|c|c|c|c|c|}
\hline Alginate & $\begin{array}{c}\text { Thickness } \\
(\mathrm{mm})\end{array}$ & $\begin{array}{c}\text { Tensile } \\
\text { strength } \\
(\mathrm{MPa})\end{array}$ & $\begin{array}{c}\text { Elongation } \\
(\%)\end{array}$ & $\begin{array}{c}\text { Water } \\
\text { solubility } \\
(\%)\end{array}$ & $\begin{array}{c}\text { WVTR } \\
\left(\mathrm{g} / \mathrm{mm}^{2} / 24 \mathrm{~h}\right)\end{array}$ \\
\hline $2 \%$ & $0.058 \pm 0.008^{\mathrm{b}}$ & $0.519 \pm 0.349^{\mathrm{c}}$ & $40.520 \pm 7.086^{\mathrm{b}}$ & $1.938 \pm 0.017^{\mathrm{b}}$ & $56.730 \pm 2.211$ \\
\hline $3 \%$ & $0.088 \pm 0.008^{\mathrm{ab}}$ & $0.534 \pm 0.169^{\mathrm{c}}$ & $82.555 \pm 0.560^{\mathrm{a}}$ & $3.916 \pm 0.675^{\mathrm{ab}}$ & $49.417 \pm 0.477$ \\
\hline $4 \%$ & $0.142 \pm 0.008^{\mathrm{ab}}$ & $0.796 \pm 0.000^{\mathrm{bc}}$ & $81.707 \pm 0.707^{\mathrm{a}}$ & $5.320 \pm 0.115^{\mathrm{ab}}$ & $51.019 \pm 1.393$ \\
\hline $5 \%$ & $0.167 \pm 0.083^{\mathrm{ab}}$ & $1.857 \pm 0.433^{\mathrm{ab}}$ & $70.430 \pm 0.830^{\mathrm{a}}$ & $6.493 \pm 1.569^{\mathrm{ab}}$ & $51.389 \pm 0.398$ \\
\hline $6 \%$ & $0.220 \pm 0.008^{\mathrm{a}}$ & $3.097 \pm 0.384^{\mathrm{a}}$ & $86.682 \pm 5.090^{\mathrm{a}}$ & $8.690 \pm 2.892^{\mathrm{a}}$ & $45.477 \pm 6.262$ \\
\hline Standard & Max 0.25 & Min 3.92 & Min 70 & & Max 10 \\
\hline
\end{tabular}

\subsection{Tensile strength}

Tensile strength is the maximum tensile force in the film until it is cut off [14]. In alginatebased edible films mechanical properties such as tensile strength are strongly influenced by conditions of relative humidity, so that the higher the humidity the smaller the tensile strength [15]. Table 1 shows that variations in alginate concentration have a significant effect on the tensile strength of edible films. The highest tensile strength value was obtained in the treatment of $6 \%$ alginate with a value of $3.097 \pm 0.384 \mathrm{MPa}$; followed by treatment of $5 \%, 4 \%, 3 \%$, and $2 \%$ alginate as $1.857 \pm 0.433 \mathrm{MPa}, 0.796 \pm 0,0004 \mathrm{MPa}, 0.534 \pm 0.169$ $\mathrm{MPa}$, and $0.519 \pm 0.349 \mathrm{MPa}$, respectively. The higher the concentration of alginate, the higher the tensile strength produced. This is because the increasing number of monomers that bind to each other causes more film matrices to be formed, thus requiring greater force to break edible film [16].

According to Japan Industrial Standard (JIS) from Setyaningrum et al. [13], the standard of tensile strength of edible films was at least $3.92 \mathrm{MPa}$ so that none of the five treatments meet the standard. The near-standard tensile strength was achieved by treatment of $6 \%$ alginate with a tensile strength of $3.097 \pm 0.384 \mathrm{MPa}$. The results of tensile strength values obtained in this study were lower than those of Santana and Kieckbusch [2] which made edible film alginate with tensile strength values of $116.3 \pm 7.0$ to $119.4 \pm 10.6 \mathrm{MPa}$; and also lower than Aziz et al. [17] which made composite edible films of alginate, glycerol and castor oil with tensile strength values of $30.02 \pm 3.42$ to $48.15 \pm 1.25 \mathrm{MPa}$.

\subsection{Elongation}

The high elongation value or breaking strength is very important for edible films to be resistant to normal pressure during their application to food [18]. In alginate-based edible films, moisture conditions can affect elongation. High environmental relative humidity conditions will increase the value of elongation, so that the edible film will increase due to 
the nature of the alginate which is hydrophilic and absorbs water from the environment [15]. The elongation value of the edible film can be inversely proportional to the value of the tensile strength. Low elongation value, the value of tensile strength is high, and vice versa on edible film with a high elongation value, the tensile strength is low. This is due to the molecular bond between the polymer and the plasticizer in the form of glycerol and olive oil which can reduce the tensile strength but increase the value of film elongation [19].

Based on Table 1, it is known that the variation in alginate concentration has a significant effect on the value of elongation. The elongation value obtained in the treatment of $2 \%, 3 \%, 4 \%, 5 \%$, and $6 \%$ alginate were $40,520 \pm 7,086 \%, 82.555 \pm 0.560 \%, 81.707 \pm$ $0.707 \%, 70.430 \pm 0.830 \%$, and $86.682 \pm 5.090 \%$, respectively. Based on JIS 1975 , the standard elongation of edible films is at least $70 \%$. Among the five treatments, treatment of $3 \%, 4 \%, 5 \%$ and $6 \%$ had elongation values that were in accordance with the JIS standard. The best treatment for elongation was produced in the treatment of $6 \%$ alginate which had the highest elongation value of $86.682 \pm 5.090 \%$. The results of the edible film elongation values in this study were higher than those of Aziz et al. [17] which made composite edible film alginate, glycerol and castor oil with elongation values between $12.60 \pm 0.48 \%$ to $15.86 \pm 11.12 \%$.

\subsection{Total soluble matter}

The solubility test aims to determine the ability of edible film to hold water. The high solubility indicates that edible films are easily soluble in water and the ability to hold water is reduced. According to Rusli et al. [16] the high solubility value is related to the biodegradation of the edible film, so that the higher the solubility, the edible film will be more easily degraded. Table 1 shows that the treatment of the alginate concentration used to make edible film has an effect on its solubility. This is because alginate is hydrophilic, so the high concentration of alginate causes edible film to absorb more water and more easily dissolve in water. At high concentrations, polysaccharides do not bind to glycerol, but bind to water molecules through hydrogen bonds so that the film matrix formed by its compactness will decrease. Even hydrophilic alginate will easily dissolve in water because of the reduced bond of alginate molecules with glycerol.

Based on Table 1 it can be seen that the lower the solubility value is better because it indicates that edible film will be more resistant to water absorption. The treatment of $2 \%$ alginate showed the lowest solubility value which was $1.938 \pm 0.017 \%$. The low solubility value in each treatment was also influenced by the soaking treatment with $4 \% \mathrm{CaCl}_{2}$ for 10 minutes in the final process of making edible film, as a crosslinking agent that binds to the film matrix and protects the film structure from disintegration due to dissolution. This is also supported by the research of Santana and Kieckbusch [2] which made alginate edible film with the addition of glycerol, then made a comparison between edible films which were not immersed with $3 \% \mathrm{CaCl}_{2}$ and which were immersed with $3 \% \mathrm{CaCl}_{2}$. The result showed that edible film alginate which is not immersed in $3 \% \mathrm{CaCl}_{2}$ dissolves $100 \%$ in water while edible film alginate treated with soaking $\mathrm{CaCl}_{2} 3 \%$ has a solubility value of $13.5 \pm 2.1 \%-16.3 \pm 1.9 \%$, so that the solubility value produced in this study is lower.

\subsection{Water vapor transmission rate (WVTR)}

The WVTR is the rate of flow of water vapor that moves from a unit area and under certain conditions [20]. WVTR is measured by the gravimetric method with periodic weighing of plates containing desiccants which are covered with edible film sheets. This test is carried out to determine the ability of edible film to resist water transfer. Based on the results of the 
ANOVA test showed that the treatment of the alginate concentration used did not significantly affect the WVTR. Environmental conditions such as RH and temperature when making edible films can affect the barrier properties of the film, especially the nature of holding the water. Alginate film can absorb water from the environment and increase its plasticity so that water is easier to diffuse. Temperatures that are too high can cause polymer molecules to immobilize so that a compact film is not formed and increases its permeability to water vapor [21].

Based on JIS 1975 the standard of water WVTR for edible films is a maximum of 10 $\mathrm{g} / \mathrm{m}^{2} / 24$ hours. None of the five treatments met the standard, but the lowest value of the WVTR was generated by the treatment of $6 \%$ alginate with a value of $45,477 \pm 6,262$ $\mathrm{g} / \mathrm{m}^{2} / 24$ hours. Because the amount of glycerol used is the same for each treatment, the concentration of alginate used in film making influences the value of the WVTR because the number of molecules that bind to glycerol varies. According to Dewi et al. [22], glycerol will cause a reduction in molecular density so that free space in the film matrix can be formed which facilitates the diffusion of water and gas, so that low alginate concentrations have more free space in the film matrix compared to edible films with high alginate concentrations. The results of the edible film WVTR in this study were lower than that of Murdinah et al. (2007) [23] which makes composite alginate, gluten and beeswax films with a value of WVTR between $154.34-284.40 \mathrm{~g} / \mathrm{m}^{2} / 24$ hours. This is because the alginate concentration used in this study is greater, so that the polymer molecular bond is denser and produces a lower value of the WVTR.

\section{Conclusion}

The characteristics of edible film consisting of thickness, tensile strength, elongation, solubility and water vapor transmission rate, are influenced by the concentration of alginate used in the manufacture of edible films. Based on the research it was found that the treatment of $6 \%$ alginate concentration showed optimal results and approached the character standard with a thickness of $0.227 \pm 0.008 \mathrm{~mm}$, tensile strength $3.097 \pm 0.384$ $\mathrm{MPa}$, elongation $86.668 \pm 5.090 \%$, solubility $8.690 \pm 2.892 \%$ and water vapor transmission rate $45.47 \pm \pm 6,262 \mathrm{~g} / \mathrm{m}^{2} / 24$ hours.

\section{References}

1. J.R. Jambeck, G. Roland, W Chris, R.S. Theodore, P. Miriam, A. Anthony, N. Ramani, L.L. Kara, Mar. Pollut. 345 (2015)

2. A.A. Santana, T.G. Kieckbusch, Braz. J. Chem. Eng. 30 (2013)

3. A.L Brody, Packaging-Edible Packaging (Food Technology, Chicago, 2005)

4. A. Manab, Jurnal Ilmu dan Teknologi Hasl Ternak 3 (2008)

5. Pereda, M., A. Guillermina, E.M. Norma, Carbohydrate Polymers 87 (2012)

6. G. Anward, H. Yusuf, R. Nur, Jurnal Teknologi Kimia dan Industri 2 (2013)

7. A. Alemán, N. Blanco-Pascual, M.P. Montero, M.C. Gómez-Guillén, Food Hydrocol. 56 (2016)

8. W. Setiani, S. Tety, R. Lena, Jurnal Kimia Valensi 3 (2013)

9. ASTM E 96, Standard Test Method for Water Vapor Transmission of Materials. American Society for Testing and Materials (1995)

10. J. Wang, J. Sang, F. Ren, Eur. Food Res Tec. 231 (2010)

11. E. Tavassoli-Kafrani, H. Shekarchizadeh, M. Masoudpour-Behabadi, Carbohydr. Polym. 137 (2016)

12. S. Galus, A. Lenart, J. Food Eng. 115 (2013) 
13. A. Setyaningrum, K.S. Ni, H. Jaya, Natural Science: Journal of Science and Technology 6 (2017)

14. S. W. Murni, H. Pawignyo, D. Widyawati, N. Sari, Prosiding Seminar Nasional Teknik Kimia Kejuangan, ISSN 1693-4393 (2013)

15. P. Cazon, G. Velazquez, J.A. Ramiez, M. Vazquez, Food Hydrocoloid. 68 (2017)

16. A. Rusli, Metusalach, Salengke, M. M. Tahir, JPHPI 20 (2017)

17. M. S. A. Aziz, H. E. Salama, M. W. Sabaa, LWT - Food Sci. and Tech 96 (2018)

18. M. Tanaka, S. Ishizaki, T. Suzuki, R. Takai, Journal of Tokyo University of Fisheries 67 (2001)

19. A. Purwanti, Jurnal Teknologi 3 (2010)

20. D. A. Diova, Y. S. Darmanto, L. Rianingsih, Jurnal Pengolahan dan Bioteknologi Hasil Perikanan 2 (2013)

21. J. W. Rhim, T. H. Shellhammer, Lipid-based edible films and coatings, in J. H. Han (Ed.). Innovations in Food Packaging, Elsevier Academic Press (2005)

22. N. L. G. Dewi, B. Admadi., A. Hartiati, Jurnal Rekayasa dan Manajemen Agroindustri 5 (2017)

23. Murdinah, M. Darmawan, D. Fransiska, Jurnal Pascapanen dan Bioteknologi Kelautan dan Perikanan 2 (2007) 